\title{
HISTORICIDADE E INTERDISCURSO: PENSANDO A EDUCAÇÃO EM CIÊNCIAS NA ESCOLA BÁSICA
}

\section{Historicity and interdiscourse: considering Science Education in the basic school}

\author{
Maria José P. M. de Almeidal
}

Resumo: É discutida a possibilidade de diferentes abordagens da dimensão histórica na História da Ciência e apontada a necessidade de que elas sejam explicitadas quando se pensa a utilização da História da Ciência no ensino da Ciência.

Unitermos: História da Ciência, Ensino da Ciência, historiografia, interdiscurso.

Abstract: This paper discusses the possibility of different approaches for the historic dimension in the History of Science and points to the necessity to make them explicit when one thinks about the use of the History of Science in the teaching of Science.

Keywords: History of Science, Science Teaching, historiography, interdiscourse.

\section{A História da Ciência no Ensino da Ciência}

$\mathrm{Na}$ educação em ciências, enquanto área de estudo e pesquisa, a História das Ciências tem sido focalizada sob diferentes perspectivas, tendo em vista o ensino escolar. Vou me referir aqui a alguns trabalhos selecionados entre os olhares de autores brasileiros que remetem para esse uso. Ao mencionar esses trabalhos, o propósito não é o de fazer uma ampla revisão bibliográfica, mas sim apresentar alguns exemplos de funcionamento da história da ciência na escola básica.

Assumindo que a abordagem histórica pode ser útil em cursos de Física, Castro e Carvalho (1992), preocupadas com a questão de como utilizar a História da Ciência, assumem o construtivismo como pressuposto e apresentam resultados do desenvolvimento em aula de atividades que incluem essa abordagem. As autoras chegam, entre outras conclusões, à de que, mesmo não sendo possível estabelecer paralelismos entre o estudante e o cientista, é possível identificar situações que revelam semelhanças de raciocínio entre um e outro. Num outro exemplo de utilização da História da Ciência como instrumento auxiliar do professor na solução das dificuldades dos estudantes, e também na reflexão sobre a natureza da ciência, Barros e Carvalho (1998) trabalham com uma programação voltada para a evolução das idéias em óptica. Bastos (1998), com uma programação pedagógica que inclui acontecimentos relacionados à pesquisa médica sobre febre amarela no período de 1881 a 1903, é outro autor que também verifica o funcionamento da História da Ciência em sala de aula. Souza e Almeida (2001), com a perspectiva de focalizarem mais diretamente o funcionamento da leitura pelos estudantes, detêm-se nas condições de produção em que ela ocorre e descrevem algumas interpretações dos estudantes ao lerem textos originais de cientistas que pensaram a fotossíntese. As autoras concluem que os estudantes, de alguma forma, perceberam limites no seu conhecimento e, também, uma certa incompletude na Ciência, quando evidenciaram falhas no conhecimento dos próprios cientistas.

Nos estudos citados os autores apresentam trabalhos, realizados em aulas de disciplinas da área das ciências, com temas do conteúdo científico, recorrendo à abordagem histórica com a finalidade de melhor atingirem objetivos educacionais. Por outro lado, alguns trabalhos estudam

${ }^{I}$ gepCE FE Unicamp.Apoio CNPq. (e-mail: mjpma@unicamp.br) 
tópicos da História da Ciência sem se voltarem para o seu funcionamento em sala de aula. É o caso de Silva e Martins (2003) que, embora não apresentando dados de análise do funcionamento em aula, referem-se a um tema específico, o trabalho sobre luz e cores de Newton, e fazem uma reflexão sobre questôes que podem ser abordadas na escola, evidenciando a preocupação com os cuidados para que não seja apresentada uma visão mítica da ciência e uma visão distorcida do que consideram o método científico.

Um outro autor, Pessoa Jr. (1996), também numa reflexão sobre o uso da história da ciência, ao procurar responder a questão "quando a abordagem histórica deve ser usada no ensino de ciências?", comenta possibilidades, tanto para o uso quanto para o não uso da História da Ciência no ensino de ciências. Segundo o autor, se quisermos que os estudantes conheçam as leis da área e resolvam equaçóes, ou se quisermos que eles resolvam problemas práticos, talvez a História da Ciência não tenha um papel importante. Preocupado em pensar a história do quê, para quem e quando, embora se refira a várias finalidades do ensino para as quais considera que a História da Ciência tem um papel bastante importante, o autor também, entre outros questionamentos, pergunta se todas as subáreas de uma ciência são igualmente propícias ao trabalho com História da Ciência. E ao responder, levanta a possibilidade de que, por exemplo, com relação à física quântica introdutória, "[...] a abordagem tradicional que parte de um relato histórico de experimentos decisivos seja menos didática do que uma abordagem que faça uso de experimentos recentes mais simples." (p. 5). Possivelmente, essas reflexōes do autor foram feitas em relação ao ensino superior, mas elas me levaram a pensar numa problemática que acredito ser abrangente aos diferentes níveis de ensino.

Essa problemática se refere ao questionamento sobre a natureza do discurso que, se colocado em funcionamento na mediaçẵo com os estudantes, permitiria que se falasse em abordagem histórica no ensino de ciências. Neste artigo, apresento uma reflexão sobre essa questão. E, como tenho notado que, na bibliografia da área de ensino de ciências a discussão sobre o uso da História da Ciência, aparentemente, tem sido contemplada mais pela sua dimensão "ciência" do que pela da "história", busquei caracterizar que aspectos da natureza do discurso de história da ciência contemplam essa outra dimensão.

\section{História e historicidade}

Neste item procuro abordar possíveis semelhanças e caracterizar diferenças entre a maneira de produzir conhecimento, que admiti como sendo histórico, em diferentes áreas, buscando uma compreensão para a noção de historicidade.

Recorro inicialmente ao trabalho de autores dedicados ao estudo de grupos humanos que habitaram e ainda habitam o nosso continente. Sob uma perspectiva evolutiva biocultural, Hubbe et al. (2003) formulam a pergunta "Existem evidências concretas sobre nosso passado, ou tudo que se diz é um 'chute'?” (p. 13). E procurando responder a essa questão, os autores falam em vestígios arqueológicos encontrados em elementos da cultura material; entre outros: instrumentos e utensílios domésticos e objetos ou indícios de manifestações artístico-religiosas. E, referindo-se a esses achados comentam que "a análise conjunta desses vestígios pode revelar muito sobre os hábitos, os costumes, a alimentação, a saúde e o mundo simbólico desses povos.” (p. 13).

Nesse texto, é interessante notar a preocupação dos autores em desmitificar a imagem dos pesquisadores dessa área como "Indiana Jones", o arqueólogo da trilogia cinematográfica de Steven Spielberg, e assemelhá-los ao detetive Sherlock Holmes das histórias policiais de Sir Arthur Conan Doyle, o escritor inglês, o mesmo citado por Einstein e Infeld (1962) para ilustrar a maneira como o cientista trabalha: 


\begin{abstract}
Em quase todo o romance policial, desde os admiráveis contos de Conan Doyle, chega um ponto em que o investigador colige todos os fatos de que necessita para solucionar pelo menos alguma fase de seu problema. Esses fatos se mostram incoerentes e inteiramente sem relação entre si. Contudo, o grande detetive percebe não serem necessárias mais investigaçōes no momento e que somente o raciocínio levará a uma correlação dos fatos coligidos. (p. 14)
\end{abstract}

Entretanto, as semelhanças na maneira como o conhecimento é produzido em áreas de conhecimento tão diferentes quanto aquelas a que se dedicam Hubbe et al., e Einstein e Infeld não resistem a um olhar mais aprofundado.

Autor de ensaios sobre a historiografia contemporânea, Ginzburg (1990), num desses ensaios, comenta por que a história nunca conseguiu se tornar uma ciência galileana. $\mathrm{O}$ autor se refere ao paradigma científico centrado na física de Galileu, pautada no emprego da Matemática e no chamado 'método experimental', que implicam quantificação e repetibilidade dos fenômenos, diferentemente de um grupo de disciplinas que o autor chama de indiciárias, as quais, segundo ele, não entram nos critérios de cientificidade dedutíveis daquele paradigma. São disciplinas qualitativas, cujos objetos são casos, situações e documentos individuais, mesmo que o indivíduo seja um grupo ou uma sociedade inteira. Nessas disciplinas, não cabe a repetibilidade e a quantificação pode ser admitida apenas em funções auxiliares.

Ginzburg também se refere à busca de um paradigma científico válido para esse outro conjunto de disciplinas, nas quais a produção de conhecimento supõe uma atitude orientada para a análise de pistas, sintomas, indícios. "Se a realidade é opaca, existem zonas privilegiadas - sinais, indícios - que permitem decifrá-la.” (p. 177). E, referindo-se especificamente à história, ele aponta o conhecimento histórico como indireto, indiciário e conjetural. E comenta ainda que, "quando as causas não são reproduzíveis, só resta inferi-las a partir dos efeitos." (p. 169).

Por outro lado, embora remeta suas exemplificações para várias disciplinas, nas quais considera que há relevância no estudo de fenômenos observados quanto à sua evolução no tempo, como a História, a Arqueologia, a Geologia, a Astronomia Física e a Paleontologia, o autor comenta que é fundamental a distinção entre natureza (inanimada ou viva) e cultura. Comentário que, certamente, faz no sentido de ressaltar diferenças na maneira de produzir conhecimento mesmo de uma para outra dessas disciplinas.

Essas consideraçôes, destacadas do texto de Ginzburg, me parecem suficientes para notarmos que, em se tratando da história das ciências da natureza, mesmo que tratemos da história de conhecimentos que acreditamos terem sido produzidos segundo o paradigma galileano, não temos mais do que indícios e sinais sobre como teria ocorrido essa produção.

Entretanto, é passando para a argumentação de um outro historiador, Pierre Raymond (1979), que busco mais diretamente refletir sobre relações mantidas entre a história das ciências e a história. Para esse autor, em se tratando da História da Ciência, deve existir a exigência de que a palavra 'história' mantenha o mesmo sentido que quando se trata da história dos historiadores, ou, segundo ele, “[...] que remeta à tentativa de totalização dos mecanismos econômicos, sociais, políticos e ideológicos, numa unidade mais ou menos coerente, mais ou menos explosiva." (p. 15). E referindo-se à Física, ele afirma que o espaço das respostas adquiridas, não escapa à história, pois:

\footnotetext{
[...] a sistematicidade não existe no estado puro, estando sempre submetida a normas pedagógicas de acesso, que implicam formas de exposição que variam no interior de campos historicamente diversos e são diferentes da conceitualização escrita - ou antes, a conceitualização 'pura' é sempre inserida em formas não científicas de exposiçāo. (p. 17).
} 
$\mathrm{O}$ autor ainda acrescenta que, aquilo que faz com que um resultado seja considerado adquirido e situado num contexto teórico, não é eterno. Ou, em suas palavras:

[...] um fenômeno não é explicado, um teorema não é demonstrado, em geral. Eles não o são do mesmo modo pelo senso comum e pelo cientista: este exige sempre uma explicação em função de um certo conjunto teórico já adquirido, uma demonstração segundo formas já definidas, mas o adquirido, o definido, periodicamente reorganizados, säo históricos. (p. 17-18).

E fornece também uma posição sobre a ciência experimental:

\begin{abstract}
[...] uma ciência experimental não é um espaço teórico, mas a relaşão entre um espaço teórico e um espaço real, e esta relaçäo particular submete a ciência considerada a uma exterioridade: o real estudado é, ele próprio, historicamente variável e surge sob diferentes aspectos segundo os momentos. (p. 18).
\end{abstract}

Ao examinar teorias relativas à historicidade da História das Ciências, o autor questiona como se pode pretender chegar a uma história da produção dos mais diversos resultados teóricos, em se tratando de uma tentativa de historicização das pesquisas, sem construir a teoria das condiçôes de sua produção. Critica a recorrência a partir do presente sobre o passado, nos moldes do que chama de projeto de uma epistemologia histórica, referindo-se a Gaston Bachelard, e também questiona a arqueologia do saber de Michel Foucault, mesmo expondo como relevante o fato dessa teoria ter colocado em ressonância as diversidades científicas e as discursividades exteriores. Sua crítica aponta no sentido de considerar a arqueologia do saber uma doutrina apoiada por regras, e duvidar que dessa maneira ela possa dar lugar a uma história. Posicionado-se a favor da teoria dialética, Raymond, entre outros comentários, afirma que:

\title{
[...] toda a explicação histórica deve fazer intervir uma distribuição social dos instrumentos teóri- cos e materiais da produção cientifica e das concep̧ōes mais ou menos latentes dos cientistas, infor- mados pelas diversas filosofias dominantes. (p. 31).
}

E ainda considera que "[...] o problema de uma história das ciências é conceber a distribuição social das forças produtivas científicas e as relaçōes (filosóficas) de produção." (p. 31).

No entanto, a posição de Pierre Raymond é apenas uma das assumidas entre os historiadores. E para ilustrar essa afirmação, volto-me para um autor que diz se posicionar como pósmoderno, Keith Jenkins (2001). Diferentemente de Raymond, este autor, assumindo uma perspectiva discursiva, admite que uma das principais rupturas na produção do conhecimento histórico se deve a Foulcault, questiona a preocupação em produzir uma síntese totalizante e aponta para diferentes modos de narrar a história. Propondo-se, nessa obra, a responder a questão o que é a história, ele, depois de discutir relaçóes de poder e ideologia no trabalho dos historiadores profissionais, encaminha a questão de maneira diferente, perguntando para quem é a história.

Em sua argumentação considera "[...] que a história constitui um dentre uma série de discursos a respeito do mundo" (p. 23), admite que história e passado são coisas diferentes, ou seja "[...] a história, embora seja um discurso sobre o passado, está numa categoria diferente dele." (p. 24), diz que seria preferível a utilização do termo 'passado' para tudo que passou em todos os lugares, e propóe o uso da palavra historiografia para os escritos dos historiadores, sendo a história o que estes fazem com o passado.

Já quanto à conciliação do passado com a história, o autor fala em três campos teóricos: a epistemologia, a metodologia e a ideologia. Em suas palavras: 


\begin{abstract}
[...] nós vamos colocar a questão de como histórias especificas vieram a ser elaboradas segundo um e não outro molde, em termos não só epistemológicos, mas também metodológicos e ideológicos. Nesse ponto, o que é possivel saber e como é possivel saber interagem com o poder. Em certo sentido, porém, isso só acontece - e trata-se agora de algo que precisamos enfatizar - por causa da fragilidade epistemológica da história. Porque, se fosse possivel saber de uma vez por todas, hoje e sempre, então não haveria mais necessidade de escrever história, pois qual seria o propósito de um semnúmero de historiadores ficarem repetindo a mesmissima coisa da mesmissima maneira o tempo todo? A história (os constructos históricos, e não o 'passado elou futuro') pararia. (p. 31).
\end{abstract}

E acrescenta mais adiante que "[...] não importa o quanto a história seja autenticada, amplamente aceita ou verificável, ela está fadada a ser um constructo pessoal, uma manifestação da perspectiva do historiador como 'narrador"' (p. 32). Em sua exposição, a história é menos do que o passado, pois os historiadores só conseguem recuperar fragmentos e não o todo, mas, por outro lado, de certa maneira, pela possibilidade de ver as coisas em retrospecto, sabemos mais sobre o passado do que aqueles que nele viveram, pois "[...] o historiador descobre não só o que foi esquecido sobre o passado, mas também 'reconstitui' coisas que, antes, nunca estiveram constituídas como tal.” (p. 34). E Jenkins também comenta que, do passado não se deduz uma interpretação única, acrescentando que para ele o que determina a interpretação "[...] está para além do método e das provas - está na ideologia." (p. 36), e pergunta, inclusive, quais seriam os critérios para decidir entre diferentes interpretações, caso fosse possível chegar ao passado mais 'verdadeiro'.

Para finalizar minha incursão nessa obra de Jenkins, destaco sua abordagem da leitura. Segundo o autor "[...] nenhuma leitura, ainda que efetuada pela mesma pessoa, é passível de produzir os mesmos efeitos repetidamente." (p. 49), de modo que os autores não teriam como obrigar os leitores a aceitar suas intençóes e interpretaçóes, nem estes poderiam discernir completamente tudo o que os autores pretendiam. No entanto, o autor acrescenta que, na verdade, lemos de maneira bastante previsível, pois ocorrem consensos de caráter geral, o que ele atribui ao poder. E, voltando à ideologia, diz que se pode argumentar que: "[...] o que impede os livros de serem usados de maneira totalmente arbitrária é o fato de que certos textos estão mais próximos de outros; são menos ou mais classificáveis dentro de certos gêneros ou rótulos; [...]" (p. 50).

No que se refere a fatos e interpretação, o autor afirma que: "[...] os historiadores têm ambiçôes, desejam descobrir não apenas o que aconteceu, mas também como e por que aconteceu e o que as coisas significavam e significam." (p. 60). E acrescenta ainda: "[...] o que está em pauta não são os fatos de per si, mas o peso, a posição, a combinação e a importância que eles trazem com referência uns aos outros na elaboração de explicações.” (p. 60).

E diz mais, que:

Essa é a inevitável dimensão interpretativa, a problemática, quando os historiadores transformam os acontecimentos do passado em padröes significantes que nenhuma representação literal desses acontecimentos como fatos poderia jamais produzir. Porque, embora possam existir métodos para descobrir 'o que aconteceu', não existe absolutamente nenhum método pelo qual se possa afirmar de uma vez por todas, 'ponto-final', o que os 'fatos' significam. (p. 60)

Voltando à minha preocupação inicial, com a dimensão histórica na História da Ciência, o olhar que até aqui dirigi para diferentes perspectivas sobre a produção de conhecimento na história, me parece suficiente para tecer consideraçóes sobre o propósito deste texto, ou seja, sobre o objetivo de buscar a natureza do discurso que, se colocado em funcionamento na mediação com os estudantes, permitiria que se falasse em abordagem histórica no ensino de ciências. 
Inicialmente, reafirmo o que é explicitado por Raymond: a História da Ciência como outras histórias não pode deixar de considerar a dimensão histórica. E, dado que, as diferentes perspectivas analisadas sobre a produção historiográfica apontam no sentido de que não se pode falar em uma única natureza para a História da Ciência, concluo pela necessidade de que sejam explicitadas as perspectivas segundo as quais são realizadas narrativas historiográficas.

No item seguinte, me volto para uma abordagem do discurso científico, tendo em vista pensar, em seguida, um dos funcionamentos possíveis da história da ciência no ensino da ciência, e para tal me alicerço nas consideraçôes aqui registradas e na noção de interdiscurso conforme é compreendida pela análise do discurso de linha francesa.

\section{Discurso científico e interdiscurso}

Depois das consideraçôes enunciadas no item anterior, relativas ao discurso histórico, volto ao discurso científico, com concepções de Michel Pêcheux, teórico apontado como sendo quem deu origem à análise do discurso na sua vertente francesa. Concepções estas explicitadas como materialistas, numa abordagem na qual a dimensão histórica é constituinte.

Em Pêcheux (1988), o autor critica a idéia de que a produção dos conhecimentos consistiria no simples desenvolvimento das propriedades dos objetos, posição que segundo ele identifica a ciência com a lógica, e concebe a prática científica como triagem entre enunciados verdadeiros e falsos, negando o que se refere às condições de aparição dos enunciados, ou seja "[...] às questōes que lhes são correspondentes no interior de uma problemática historicamente determinada [...]". (p. 197). Também admite que a objetividade científica não está dissociada de tomadas de posição, pois não existe equivalência entre diferentes formulações. E, ainda no mesmo sentido, comenta que o problema está na idéia de que existe um discurso da ciência cuja característica seria o apagamento do sujeito. Em suas palavras: "O único meio de esclarecer essa confusão é reconhecer que não há 'discurso da ciência' (nem mesmo, a rigor, 'discurso de uma Ciência’) porque todo discurso é discurso de um sujeito" (p. 198).

E Pêcheux resume sua idéia sobre o assunto com três pontos que considera poderem constituir um paradoxo do ponto de vista idealista, e que para ele são a base de uma posição materialista:

- o processo de produção dos conhecimentos é um processo sem sujeito, isto é, um processo do qual todo sujeito, como tal, está ausente;

- o processo de produção dos conhecimentos se opera por meio das tomadas de posição ('demonstrações' etc.) pela objetividade científica;

- o processo de produção dos conhecimentos é um 'corte continuado'; ele é, como tal, coextensivo às ideologias teóricas, das quais ele não cessa de se separar, de modo que é absolutamente impossível encontrar um puro 'discurso científico' sem ligação com alguma ideologia. (p. 198).

Uma noção necessária à compreensão do papel da ideologia na análise do discurso, ou seja, na concepção em que Pêcheux a utiliza, é a de memória discursiva ou interdiscurso, cujo funcionamento Orlandi (1998) vai apontar ao dizer que:

A ideologia, na análise de discurso, está na produção da evidência do sentido (só pode ser 'este') e na impressão do sujeito ser a origem dos sentidos que produz, quando na verdade ele retoma sentidos préexistentes. Dai a necessidade de se pensar o gesto de interpretação como lugar da contradição: é o que 
permite o dizer do sujeito pela repetição (efeito do já-dito) e pelo deslocamento (historicização). A interpretação se faz assim entre a memória institucional (arquivo) e os efeitos da memória (interdiscurso). No domínio do arquivo a repetição congela, estabiliza, no dominio do interdiscurso a repetição é a possibilidade do sentido vir a ser outro, no movimento contraditório entre o mesmo e $o$ diferente. (p. 16).

Orlandi (2001) reforça a idéia de que na análise de discurso a ideologia é entendida como relação necessária entre os indivíduos e suas condições de existência constituída na e pela linguagem "[...] num processo que excede a consciência do sujeito." (p. 182), sendo o discurso uma rede de sentidos pela qual os sujeitos se constituem e se relacionam com o mundo.

Já quanto à relação da ideologia com o interdiscurso, ou memória discursiva, convém lembrar com Pierre Achard (1999) que "[...] o passado, mesmo que realmente memorizado, só pode trabalhar mediante as reformulações que permitem reenquadrá-lo no discurso concreto face ao qual nos encontramos." (p. 14). E essa idéia torna-se ainda mais compreensível quando Pêcheux (1999), ao comentar o texto de Achard, diz que:

\begin{abstract}
[...] a memória tende a absorver o acontecimento, como uma série matemática prolonga-se conjeturando o termo seguinte em vista do começo da série, mas o acontecimento discursivo, provocando interrupção, pode desmanchar essa 'regularização' e produzir retrospectivamente uma outra série sob a primeira, desmascarar o aparecimento de uma nova série que não estava constituída enquanto tal e que é assim o produto do acontecimento; o acontecimento, no caso, desloca e desregula os implícitos associados ao sistema de regularização anterior. (p. 52).
\end{abstract}

\title{
Implicações para o ensino
}

Antes das considerações do item anterior, ao dizer que as diferentes perspectivas sobre a produção historiográfica apontam no sentido de que não se pode falar em uma única natureza para a história da ciência, concluí pela necessidade de serem explicitadas as perspectivas segundo as quais são realizadas narrativas historiográficas.

Considero que a explicitação da perspectiva segundo a qual é feita a narrativa historiográfica pode-se constituir num fator de fortalecimento da idéia de que a compreensão de discursos referentes à ciência pode ser facilitada pela narrativa histórica. Pois dizer que esta última deve incluir a explicitação da perspectiva em que o discurso foi produzido é dizer ao narrador que se identifique como tal, enunciando seus pressupostos e, desse modo, localizando suas posiçōes enquanto narrador. De onde fala? O que o levou a dizer o que está dizendo? Por que selecionou esta ou aquela parte do discurso de um cientista? Que indícios possui para afirmar que certo acontecimento foi interpretado por determinado cientista de tal maneira? O que sustentou certa interpretação na época em que ela ocorreu?

Narrativas historiográficas que incluem respostas a questões como as que acabo de enunciar constituem discursos altamente diferenciados daqueles usuais quando o que se apresenta aos estudantes é apenas aquilo que é considerado como resultado da ciência num dado momento histórico. E mais: dadas as consideraçôes apresentadas no item anterior, torna-se bastante plausível a suposição de que esses discursos podem constituir a base de possíveis interlocuçôes com estudantes no sentido destes se relacionarem com conhecimentos relativos à ciência por meio do interdiscurso, ou seja, do funcionamento de suas próprias memórias discursivas.

Assim, as narrativas historiográficas, em funcionamento numa sala de aula, como mediadoras da memória discursiva dos estudantes, terão grande possibilidade de contribuir para associações, que eles farão com acontecimentos que desregulem os implícitos tão presentes na 
metalinguagem científica, provocando deslocamentos no discurso desses estudantes no sentido de melhor compreenderem, inclusive, essa mesma metalinguagem.

Gostaria ainda de frisar que as considerações aqui apresentadas não visam a tornar mais complexo o uso da História da Ciência no ensino da Ciência. Pelo contrário, elas não se opõem, mas vão ao encontro de vários trabalhos que têm, na Educação em Ciências, utilizado pedagogicamente o que Matthews (1995) chama de história simplificada. No dizer desse autor, "história e ciência podem tornar-se mais e mais complexas à medida que assim o exija a situação educacional” (p.177). E, referindo-se, no caso, à formação inicial ou continuada de profissionais, o autor comenta que:

\section{[...] O problema hermenêutico de interpretação na história da ciência, longe de dificultar ou impe- dir o uso da história, pode tornar-se uma boa ocasiāo para que os alunos sejam apresentados a importantes questóes de como lemos textos e interpretamos os fatos, isto é, ao complexo problema do significado: a partir de seu dia a dia, os alunos sabem que as pessoas vêem as coisas de formas diferentes; portanto, a história da ciência constitui-se num veiculo natural para se demonstrar como esta subjetividade afeta a própria ciência. (p. 177).}

E para concluir, gostaria de reafirmar a natureza histórica da História da Ciência e a possibilidade de diferentes perspectivas para a produção historiográfica; o que, longe de constituir um problema para o trabalho com História da Ciência em aulas de disciplinas científicas, foi aqui apontado, quando a perspectiva em questão for explicitada, como uma característica que tende a facilitar a mediação de tópicos da ciência aos estudantes.

\section{Referências}

ACHARD, P. Memória e produção discursiva do sentido. In: ACHARD, P. et al. Papel da Memória. Campinas: Pontes, 1999. p. 11-21.

BARROS, M. A.; CARVALHO, A M. P. de. A história da ciência iluminando o ensino de visão. Ciência \& Educação, Bauru, v. 5, n. 1, p. 83-94, 1998.

BASTOS, F. O ensino de conteúdos de história e filosofia da ciência. Ciência \& Educação, Bauru, v. 5, n. 1, p. 55-72, 1998.

CASTRO, R. S.; CARVALHO, A. M. P. História da ciência: investigando como usá-la num curso de segundo grau. Caderno Catarinense de Ensino de Física, Florianópolis, v. 9, n. 3, p. 225-237, 1992.

EINSTEIN, A.; INFELD, L. A evolução da física. Tradução Giasone Rebuá. Rio de Janeiro: Zahar, 1962.

GINZBURG, C. Mitos emblemas sinais: morfologia e história. São Paulo: Companhia das Letras, 1990.

HUBBE, M. et al. A primeira descoberta da América. Ribeirão Preto: Sociedade Brasileira de Genética, 2003.

JENKINS, K. A história repensada. São Paulo: Contexto, 2001. 117 p. 
MATTHEWS, M. R. História, filosofia e ensino das ciências: a tendência atual de reaproximação. Caderno Catarinense do Ensino de Física, Florianópolis, v. 12, n. 3, p. 164-214, 1995.

ORLANDI, E. P. Discurso e texto: formulação e circulação dos sentidos. Campinas: Pontes, 2001. 218 p.

_. Paráfrase e polissemia: a fluidez nos limites do simbólico. Rua, Campinas, n. 4, p. 9-19, 1998.

PÊCHEUX, M. Papel da memória. In: ACHARD, P. et al. Papel da memória. Campinas: Pontes, 1999. p. 49-57.

—. Semântica e discurso. Uma crítica à afirmação do óbvio. Campinas: Editora da Unicamp, 1988.

PESSOA JUNIOR, O. Quando a abordagem histórica deve ser usada no ensino de ciências? Ciência \& Ensino, Campinas, n. 1, p. 4-6, out.1996.

RAYMOND, P. A história e as ciências. Tradução Olga Magalhães. Porto: Rés, 1979. p. 15-33.

SILVA, C. C.; MARTINS, R. de A. A teoria das cores de Newton: um exemplo do uso da história da ciência em sala de aula. Ciência \& Educação, Bauru, v. 9, n. 1, p. 53-65, 2003.

SOUZA, S. C.; ALMEIDA, M. J. P. M. de. Leituras na mediação escolar em aulas de ciências: a fotossíntese em textos originais de cientistas. Pro-Posições, São Paulo, v. 12, n. 1, 2001. 